\title{
A Systematic Review of the Use of Serious Games in Science Education
}

\author{
Nuri Kara \\ Istanbul Bilgi University, Turkey \\ ORCID: 0000-0002-0115-383X
}

Received: 26 Apr 2020

Accepted: 28 Jun 2020

\begin{abstract}
The aim of this study was to conduct a systematic literature review on the use of serious games in science education between 2016 and 2020 years. A total of 39 articles were included from Science Citation IndexExpanded (SCl-Expanded), Social Science Citation Index (SSCl), Arts \& Humanities Citation Index ( $\&$ \& $\mathrm{HCl})$ and Emerging Sources Citation Index (ESCl) listed in the Web of Science database. The results showed that experiential science was the most emphasized subject area in the articles. The results also indicated that learning/academic achievement was the common examined topic in the articles. For the research designs, more than half of the articles implemented quantitative research design. Considering the data collection tools, achievement tests were the most used data collection tool. Regarding the use of sampling methods, convenience sampling was preferred in more than half of the articles. Secondary and primary school students were the most used sampling groups. The sample size of 31-100-person group was commonly chosen in the articles. Considering the data analysis methods, a majority of articles implemented descriptive analyses methods. It was also found that computer game was the most used game type. Regarding the game genres, adventure was the most preferred one in serious games.
\end{abstract}

Keywords: serious games, educational games, science education, literature review

\section{INTRODUCTION}

The trend of the use of serious games have increased in last years. Serious games are defined as games for nonentertainment purposes in a variety of fields, such as military, education, health and business (Charsky, 2010; Susi, Johannesson, \& Backlund, 2007). Education is one of the fields that several serious game practices have been used and investigated. Serious games create an interest to researchers or people in the field of education since it integrates gaming and learning features (Girard, Ecalle, \& Magnant, 2013). Similarly, "serious games use the characteristics but in a manner that allows for the use of a broader range of instructional methods" (Charsky, 2010, p. 179). There have been several recent studies investigating the effects or use of serious games in education. Vlachopoulos and Makri (2017) conducted a systematic literature review in higher education and found a positive effect of games and simulations on learning goals. Chang, Kao, Hwang, and Lin (2019) conducted an experimental study and found that the use of serious game yielded better learning performance scores of nursing students compared with the traditional instruction. Katsaounidou, Vrysis, Kotsakis, Dimoulas, and Veglis (2019) designed a serious game and found a positive impact on news verification. Alonso-Fernández, Martínez-Ortiz, Caballero, Freire, and Fernández-Manjón (2020) conducted a case study and indicated that serious games with the integration of game learning analytics can be used for measuring the knowledge acquisition. Almeida (2020) indicated a relationship between emotional intelligence skills and serious game performance scores of college students based on a mixed methods study. 
Science is a discipline of education where several serious game related studies are conducted. Serious games can provide an easy and alternative way to learners to easily experience the simulations or experiments in science (Riopel et al., 2020). According to Cheng, Chen, Chu, and Chen (2015), researchers and educators show a big interest to the use of serious games in science education. Cheng et al. (2015) also indicated that the number of research related with the effectiveness of serious games in science education has been increased recently. However, these research studies have not provided a common or proved results especially for the potential of serious games in science learning (Baek, Park, \& Han, 2016; Riopel et al., 2020). Therefore, there is a need for more research studies integrating serious games into science education. One of the aims of this paper is to show the research trends of the use of serious games in science education to offer a road map for the possible future research studies.

There have been several studies reviewing the use of serious games in science education. Riopel et al. (2020) conducted a meta-analysis of 79 empirical studies comparing the effects of using serious games on science learning versus traditional methods. Arici, Yildirim, Caliklar, and Yilmaz (2019) carried out a content and bibliometric analyses of articles published between 2013 and 2018 to reveal the research trends on the use of augmented reality in science education. Boyle et al. (2016) reviewed 143 papers published between 2009 and 2014 years to understand the impacts and outcomes of serious games on several topics including science. Cheng et al. (2015) made a systematic review of the articles published from 2002 to 2013 to show the research trends on the use of serious games in science education. Calderón and Ruiz (2015) conducted a systematic review of 102 published articles to analyze the methods and procedures used to assess serious games in different fields including science. $L i$ and Tsai (2013) performed a content analysis of 31 articles published from 2000 to 2011 to analyze the methodological and instructional trends for game-based science learning. Connolly, Boyle, MacArthur, Hainey, and Boyle (2012) analyzed 129 articles published between 2004 and 2009 to understand the effects of serious games on learning, engagement and skill improvement in a variety of topics including science learning. Based on the review studies presented above, most of them included the date before 2015 to analyze the articles for showing the research trends. In Arici et al. (2019)'s study, only, the time span was between 2013 and 2018; but they specifically investigated the use of augmented reality. Hence, the other aim of this paper is to provide the recent research trends on the use of serious games in science education by focusing on the articles which have been published between 2016 and 2020 years. Several studies aiming at revealing research trends of serious games or specific technologies in science education used main research questions related with research methods including data collection and analysis, research topics, sampling and game dimensions (Arici et al., 2019; Cheng et al., 2015). Therefore, the similar framework has been used for determining the research questions (RQ) which are listed below:

RQ 1. What were the main subject areas of the studies covered in articles on use of serious games in science education?

RQ 2. What topics were investigated in articles on use of serious games in science education?

RQ 3. What research methodologies were mostly used in articles on use of serious games in science education?

RQ 4. What data collection tools were commonly applied in articles on use of serious games in science education?

RQ 5. What sampling methods, sampling groups and sample sizes were frequently preferred in articles on use of serious games in science education?

RQ 6. What data analysis methods were commonly used in articles on use of serious games in science education?

RQ 7. What game types were used in articles on use of serious games in science education?

$\mathrm{RQ}$ 8. What game genres were mostly included in articles on use of serious games in science education? 


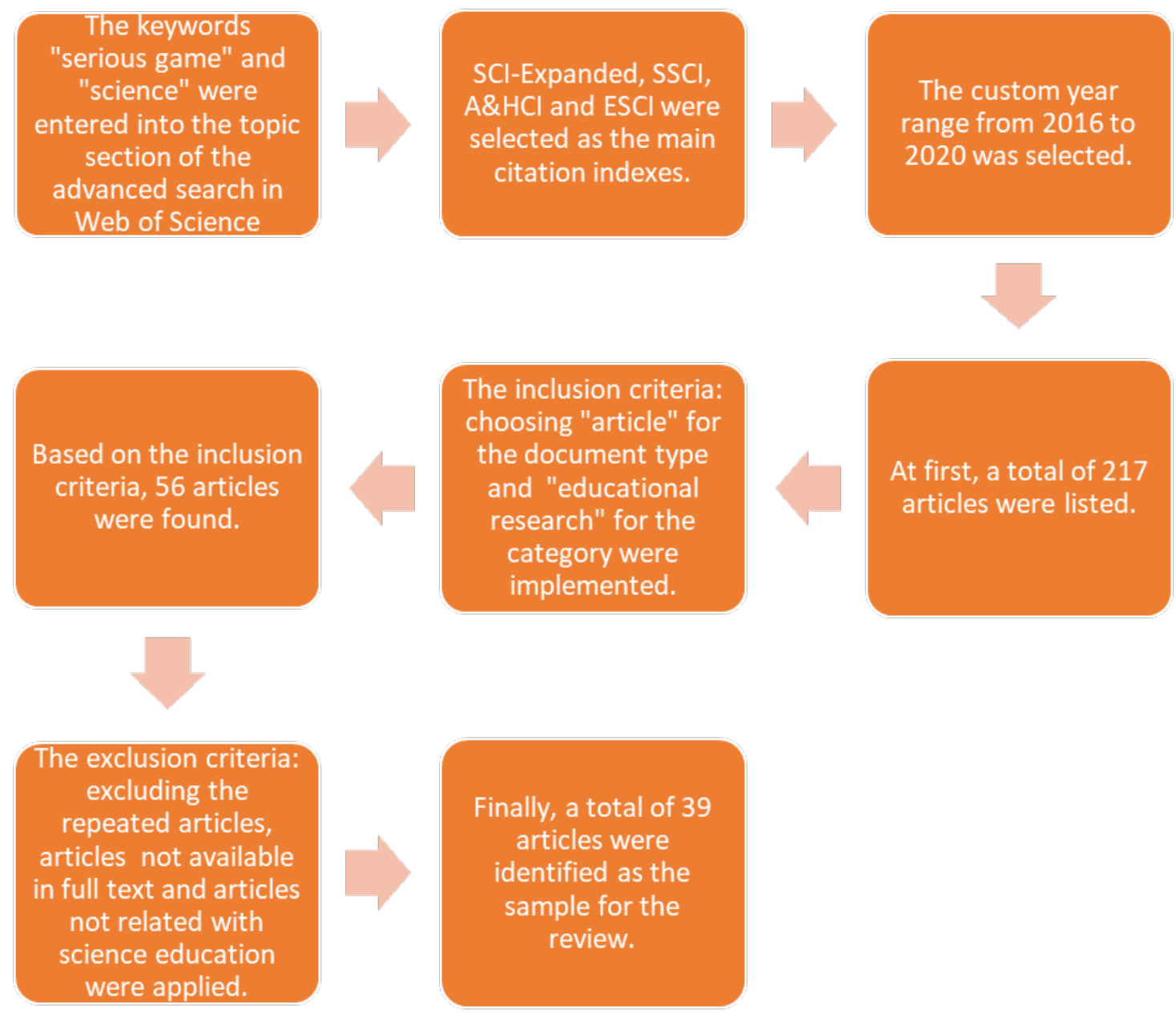

Figure 1. Article selection process of the study

\section{METHOD}

\section{Article Selection Process}

The main goal of this study is to reveal the research trends related with the use of serious games in science education between 2016 and 2020 years. For this purpose, Web of Science database was used to gather the related articles. In Web of Science interface, "serious game" and "science" terms were entered as the main topics of the search. Additionally, Science Citation Index- Expanded (SCl-Expanded), Social Science Citation Index (SSCl), Arts \& Humanities Citation Index (A\& $\mathrm{HCl}$ ) and Emerging Sources Citation Index (ESCl) were selected as the main indexes for the search. The main reason of using all indexes listing articles was to see a variety of serious research papers which can be related with the use of serious games in science education. Furthermore, "custom year range from 2016 to 2020" was determined as the time span. The advanced search was done on $30^{\text {th }}$ May 2020. Based on the initial results, 217 articles were appeared. The specific inclusion criteria were applied to limit the articles for the systematic review of the articles on the use of serious games. The first criterion was to use "Educational research" as a web of science category. Since the main goal of this study was reviewing the serious game related articles in science education it was important to see the trends in educational research. The other inclusion criterion was to use "only articles" as document types. Fifty-six articles were found after applying the inclusion criteria. Specific exclusion criteria were then implemented to finalize the articles to be reviewed. The first exclusion criterion was to exclude same articles listed more than once. The second criterion was to exclude articles that were not available in full text. The last exclusion criterion was to remove articles which were not directly related with science education. Finally, a total of 39 articles were determined as the main sample of this systematic review study. Figure 1 summarizes the main article selection process. 
Table 1. The numbers and percentages of the main subject areas

\begin{tabular}{lcc}
\hline The main subject area & Number of articles & Percentage (\%) \\
\hline Experiential Science & 7 & 17.9 \\
Biology & 5 & 12.8 \\
STEM & 5 & 12.8 \\
Learning Science & 4 & 10.3 \\
Computer Science & 4 & 10.3 \\
Physics & 3 & 7.7 \\
Game Science & 3 & 7.7 \\
Environmental Science & 2 & 5.1 \\
Space Science & 2 & 5.1 \\
Design Science & 2 & 5.1 \\
Behavioral Science & 1 & 2.6 \\
Chemistry & 1 & 2.6 \\
\hline
\end{tabular}

\section{Data Collection and Analysis}

A total of 39 articles were listed based on the systematic search of the published articles. Goktas et al. (2012)'s Publication Classification Form was utilized to collect data from the listed articles. The form includes five main categories: 1- information about the article, 2- research methodologies, 3- data collection tools, 4sampling and 5- data analysis methods. In addition to these categories, main subject area was added to the form to better understand the studies' or implemented serious games' main subjects related to science education. The category of examined topics was also added to analyze the most emphasized variables in articles. Moreover, different game genres as offered by Poole (2004) was added to the form. Furthermore, different game types (e.g computer game, mobile game, lego-based game, virtual worlds, web-based game, board game, video game and mmorpg) listed by Calderón and Ruiz (2015) was added to the form. New game types such as virtual reality (VR) game, augmented reality (AR) game and motion sensitive game were also integrated into this game type category.

The final classification form includes nine categories: 1- information about the article, 2- subject area, 3examined topics, 4- research methodologies, 5- data collection tools, 6- sampling, 7- data analysis methods, 8- game types, and 9- game genres. SPSS Statistics 26 was used to analyze the data of the reviewed articles entered to the program in accordance with the sections mentioned above. Two academicians of Faculty of Communication reviewed the data collection process to ensure that all data entered to the SPSS program was consistent with reviewed articles. The descriptive methods were implemented for data analysis.

\section{RESULTS}

\section{RQ 1. What were the Main Subject Areas of the Studies Covered in Articles on Use of Serious Games in Science Education?}

Table 1 shows the main subject areas of the articles. Based on the Table 1, experiential science $(f=7)$ was the main subject of $17.9 \%$ of the articles. Biology $(f=5)$, STEM $(f=5)$, Learning science $(f=4)$ and Computer science $(f=4)$ were also the main subject areas of more than $10 \%$ of the articles. It can be inferred from these findings that a variety of subject areas were covered in articles published from 2016 to 2020.

\section{RQ 2. What Topics were Investigated in Articles on Use of Serious Games in Science Education?}

According to the statistics shown in Table 2, several topics were examined in the articles. Based on the findings, learning/academic achievement $(f=22)$ was the most examined topic in $29.73 \%$ of the articles. Motivation ( $f=8$ ) was examined in $10.81 \%$ of the articles while cognitive attributes $(f=7)$ were investigated in $9.46 \%$ of the articles. Compared to learning/academic achievement, motivation and cognitive attributes, the other topics such as usability, attitude, engagement and etc. were examined less in articles published from 2016 to 2020 (see Table 2). 
Table 2. The numbers and percentages of the examined topics

\begin{tabular}{lcc}
\hline The dominant field & $\mathrm{f}$ & $\%$ \\
\hline Learning/academic achievement & 22 & 29.73 \\
Motivation & 8 & 10.81 \\
Cognitive attributes & 7 & 9.46 \\
Usability & 5 & 6.76 \\
Attitude & 4 & 5.41 \\
Engagement & 4 & 5.41 \\
Interest & 4 & 5.41 \\
Learning behavioral patterns & 3.05 \\
Empowerment & 3 & 2.70 \\
Scientific inquiry skills & 2 & 2.70 \\
Flow & 2 & 2.70 \\
Immersion & 2 & 2.70 \\
Self-evaluation & 2 & 1.35 \\
Perception & 1 & 1.35 \\
Misconceptions & 1 & 1.35 \\
Productive negativity & 1.35 \\
Interaction & 1 & 1.35 \\
Presence & 1 & 1.35 \\
Problem solving awareness & 1 & 1.35 \\
Computational thinking skills & 1 & 1.35
\end{tabular}

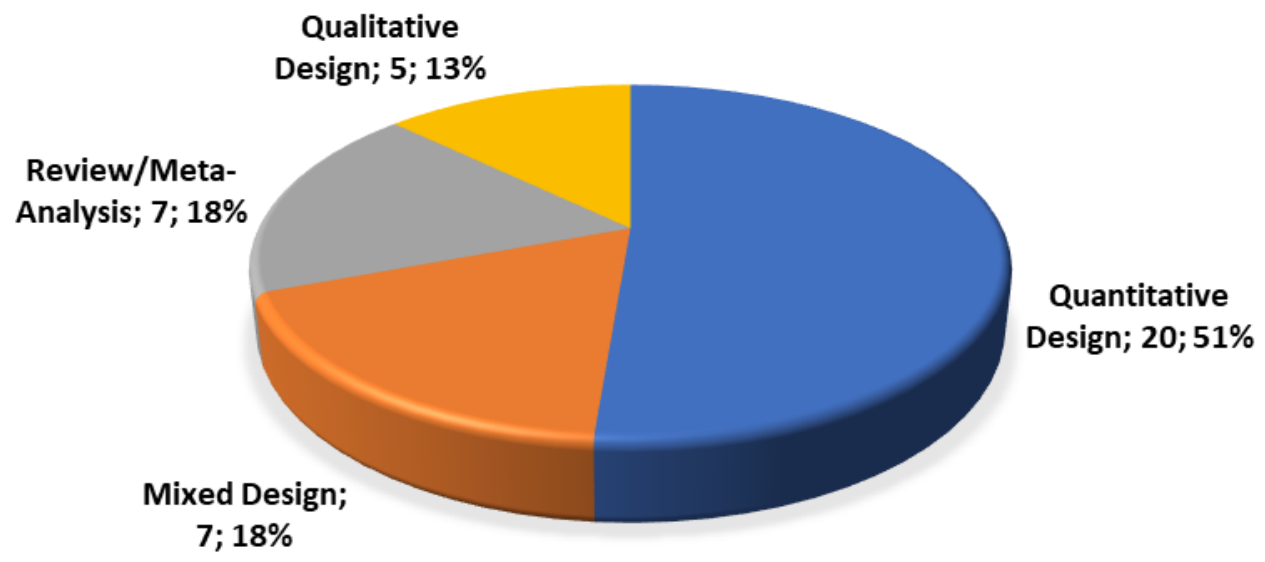

Figure 2. Percentages of research methods used in articles

\section{RQ 3. What Research Methodologies were Mostly Used in Articles on Use of Serious Games in Science Education?}

According to Figure 2, 51\% of the articles applied quantitative design, 18\% applied mixed design, 18\% applied review/meta-analysis and $13 \%$ applied qualitative design. These findings indicate that quantitative design was the common research design in more than half of the articles. In quantitative design, quasi-experimental research method $(23.1 \%)$ was the most preferred experimental method. On the other hand, descriptive methods (10.3\%) was the commonly used non-experimental quantitative method. In mixed design, triangulation (10.3\%) was the most used research method. In review/meta-analysis, researchers mostly used literature review (10.3\%) as a research method. The detailed research design and method statistics can be seen in Table 3. 
Table 3. Research methods of articles published from 2016 to 2020

\begin{tabular}{|c|c|c|c|c|}
\hline Research designs & & Research methods & $f$ & $\%$ \\
\hline \multirow[t]{5}{*}{ Quantitative } & Non-experimental & Descriptive & 4 & 10.3 \\
\hline & & Correlational & 2 & 5.1 \\
\hline & Experimental & Quasi experimental & 9 & 23.1 \\
\hline & & True experimental & 3 & 7.7 \\
\hline & & Pre experimental & 2 & 5.1 \\
\hline \multirow[t]{2}{*}{ Qualitative } & & Case study & 3 & 7.7 \\
\hline & & Phenomenological study & 2 & 5.1 \\
\hline \multirow[t]{3}{*}{ Mixed } & & Triangulation & 4 & 10.3 \\
\hline & & Explanatory & 2 & 5.1 \\
\hline & & Embedded & 1 & 2.6 \\
\hline \multirow[t]{2}{*}{ Review / Meta-analysis } & & Literature review & 4 & 10.3 \\
\hline & & Meta-analysis & 3 & 7.7 \\
\hline
\end{tabular}

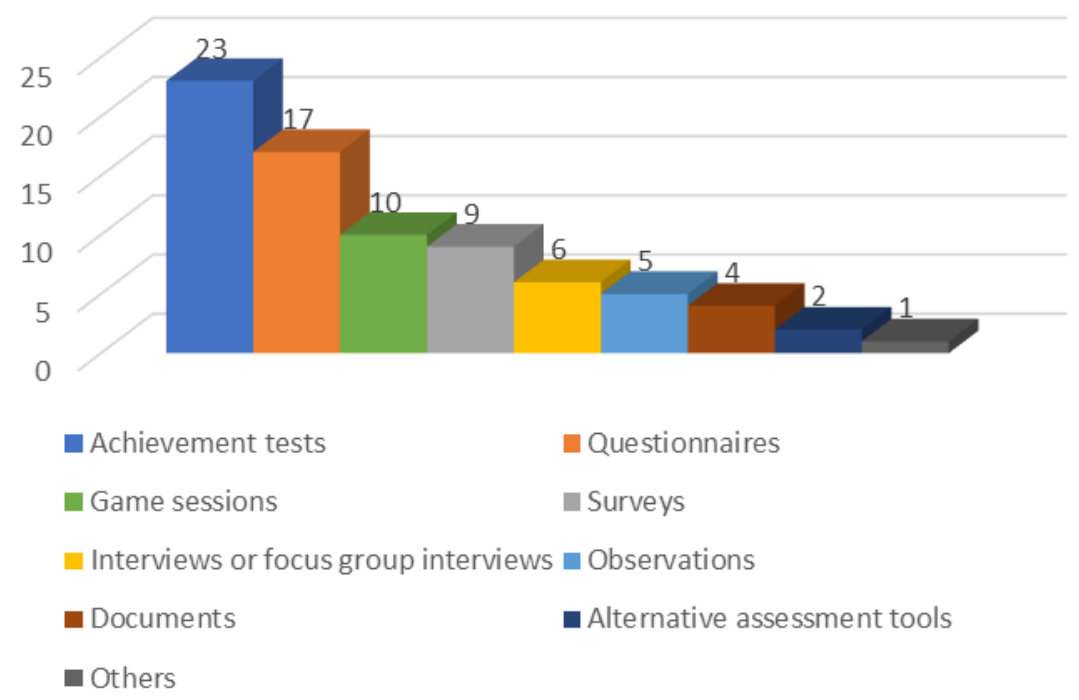

Figure 3. Frequency of the data collection tools

\section{RQ 4. What Data Collection Tools were Commonly Applied in Articles on Use of Serious Games in Science Education?}

Figure 3 shows the numbers of data collection tools used in the articles. Based on the findings, achievement tests $(f=23)$ were the most used data collection tool. Questionnaires $(f=17)$ were the second commonly used data collection tool. Game sessions $(f=10)$ were the third commonly used data collection tool to get data from the interactions of players during the game play. The higher number of using achievement tests, questionnaires and game sessions can be linked to the dominancy of quantitative research design in articles published from 2016 to 2020.

\section{RQ 5. What Sampling Methods, Sampling Groups and Sample Sizes were Frequently Preferred in Articles on Use of Serious Games in Science Education?}

Figure 4 indicates the numbers and percentage of sampling methods applied in the articles. Based on the statistics, convenience sampling (54\%) was the most emphasized sampling method. On the other hand, random sampling was preferred in $23 \%$ of the articles. The main reason of high usage of convenience sampling can be related to the easy access to the samples in quantitative, qualitative and mixed designs. 


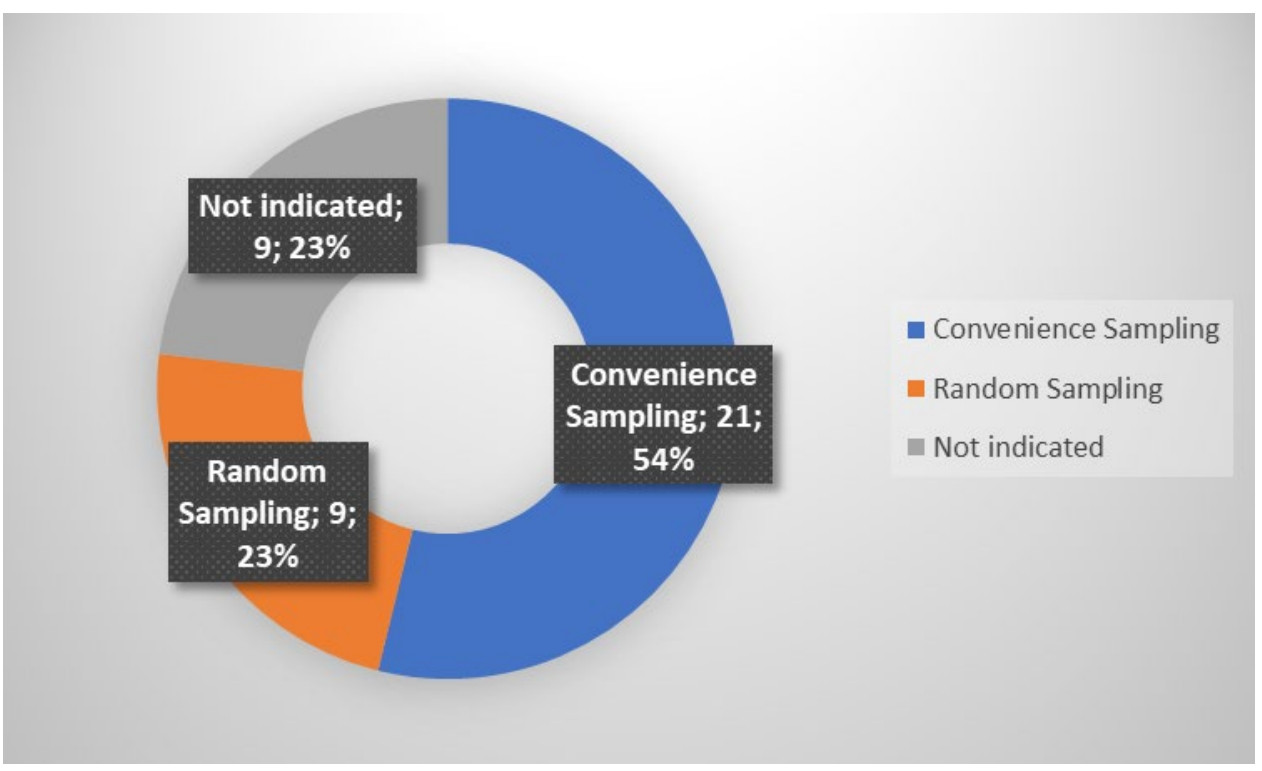

Figure 4. Frequency and percentage of sampling methods in articles

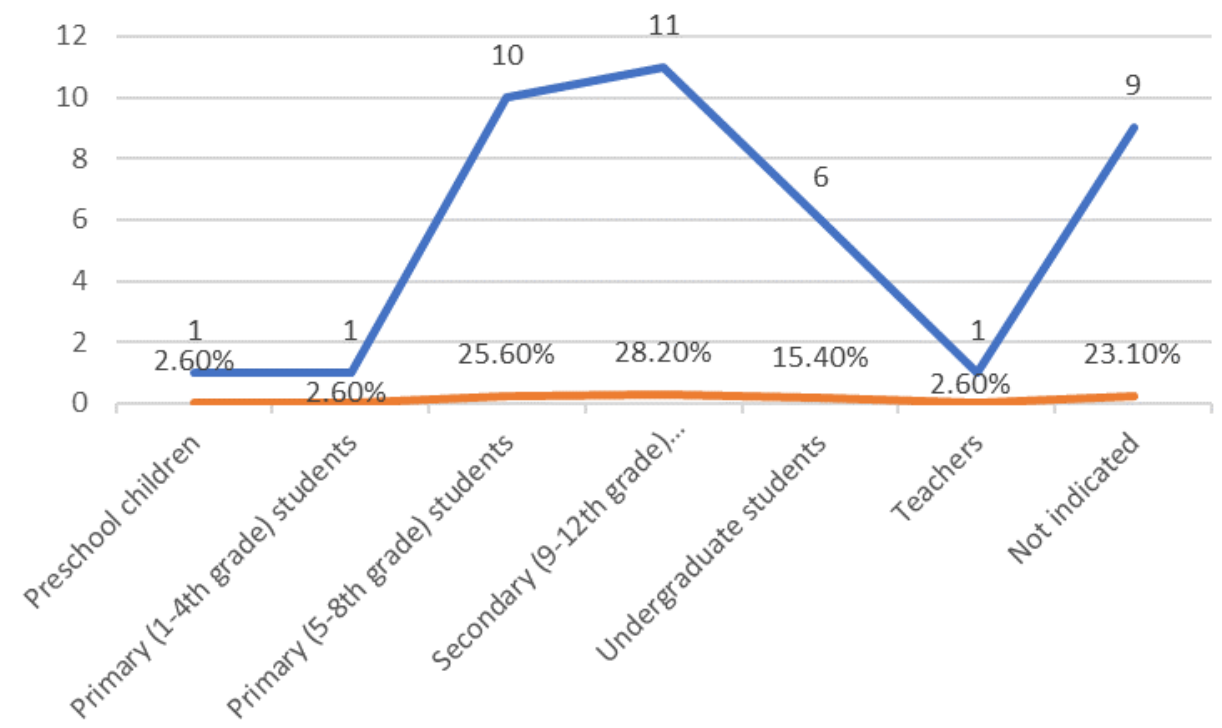

Figure 5. Frequency and percentage of sampling groups in articles

Table 4. Frequency and percentage of sample sizes in articles

\begin{tabular}{lcc}
\hline Sample sizes & $f$ & $\%$ \\
\hline $31-100$ & 15 & 38.5 \\
$101-300$ & 8 & 20.5 \\
$301-1000$ & 5 & 12.8 \\
$1-10$ & 1 & 2.6 \\
$1001-2000$ & 1 & 2.6 \\
2001 and more & 1 & 2.6 \\
Not indicated or not applicable & 8 & 20.5 \\
\hline
\end{tabular}

As shown in Figure 5 , secondary $\left(9-12^{\text {th }}\right.$ grade) students $(f=11)$ and primary $\left(5-8^{\text {th }}\right.$ grade $)$ students $(f=10)$ were the common sampling groups included in articles. Undergraduate students $(f=6)$ were also selected as samples in many articles.

Table 4 summarizes the numbers and percentages of sample sizes covered in articles published from 2016 to 2020. 31-100-person group (38.5\%) was the most used sample size in articles. In addition, 101-300-person group (20.5\%) and 301-1000-person group (12.8\%) were preferred in a substantial number of articles. 
Table 5. Data analysis methods of articles

\begin{tabular}{llcc}
\hline & & $\mathrm{f}$ & $\%$ \\
\hline Descriptive analyses & Frequencies, percentages, tables & 25 & 64.1 \\
& Means, standard deviations & 21 & 53.8 \\
& Graphs & 15 & 38.5 \\
Inferential analyses & T-tests & 8 & 20.5 \\
& ANOVA/ANCOVA & 16 & 41 \\
& Non-parametric tests & 8 & 20.5 \\
& Correlations & 11 & 28.2 \\
& Regression & 7 & 17.9 \\
& MANOVA/MANCOVA & 4 & 10.3 \\
Qualitative analyses & Factor analysis & 1 & 2.6 \\
& Others & 8 & 20.5 \\
& Content analysis & 8 & 20.5 \\
& Descriptive analysis & 5 & 12.8 \\
\hline
\end{tabular}

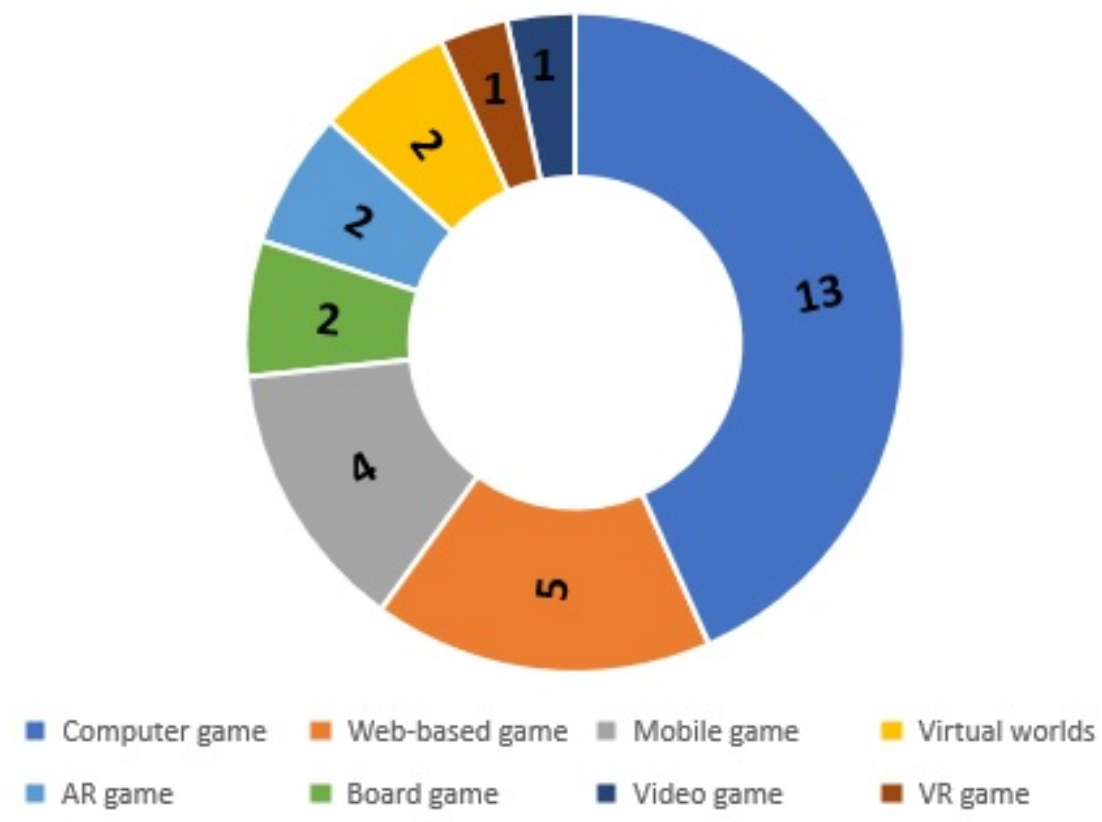

Figure 6. Frequency of game types

\section{RQ 6. What Data Analysis Methods were Commonly Used in Articles on Use of Serious Games in Science Education?}

Table 5 shows the numbers and percentages of data analysis methods used in the articles. The findings indicate that a majority of articles implemented frequencies, percentages and tables (64.1\%) as a descriptive analysis method. Additionally, means, standard deviations (53.8\%) were analyzed in a high number of articles. For inferential analyses methods, ANOVA/ANCOVA analyses (41\%) were applied in nearly half of the articles. The statistics also pointed out that several inferential analyses methods, such as correlations, nonparametric tests and T-tests were included in articles. For qualitative analyses methods, content analysis $(20.5 \%)$ was the most used data analysis method. On the other hand, descriptive analysis method (12.8\%) was used less than content analysis.

\section{RQ 7. What Game Types were Used in Articles on Use of Serious Games in Science Education?}

As can be seen in Figure 6 , computer games $(f=13)$ were the most integrated game types in serious game studies in science education. Compared to computer games, web-based games $(f=5)$ and mobile games $(f=$ 4 ) were implemented in a smaller number of articles. However, the use numbers of web-based and mobile 


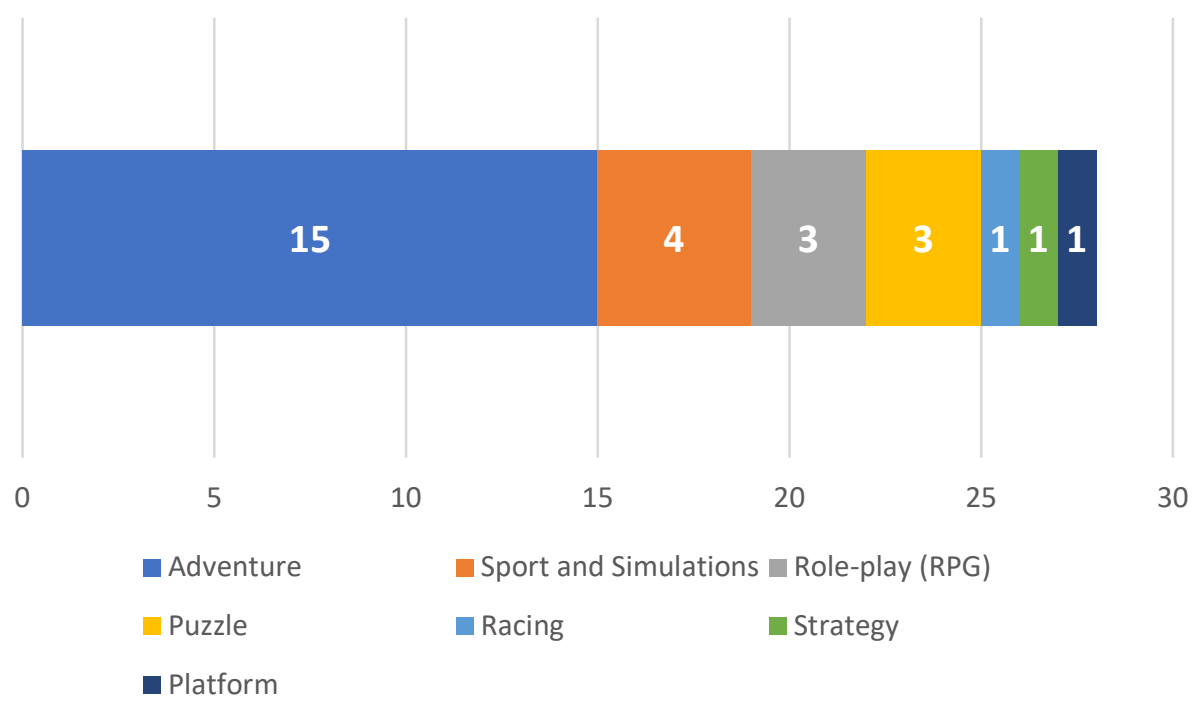

Figure 7. Frequency of game genres

games were higher than board game $(f=2)$, AR game $(f=2)$, virtual worlds $(f=2)$, VR game $(f=1)$ and video game $(f=1)$.

\section{RQ 8. What Game Genres were Mostly Included in Articles on Use of Serious Games in Science Education?}

According to the frequencies presented in Figure 7 , adventure $(f=15)$ was commonly preferred game genre in the serious games. Sport and simulation $(f=4), R P G(f=3)$ and puzzle $(f=3)$ games were also used in many articles. However, racing, strategy and platform games were chosen only in 1 article.

\section{DISCUSSION}

The main goal of this study was to systematically review of the use of serious games in science education from 2016 to 2020. There were main 8 RQs aiming at revealing recent research trends. The first RQ was related with the main subject areas of the studies covered in articles on use of serious games in science education. Based on the results of analysis, experiential science was the most emphasized subject area of the articles. Alrehaili and Al Osman (2019) investigated the effect of a virtual reality role playing serious game for experiential learining in an educational context. Similarly, McBurnett, Hinrichs, Seager, and Clark (2018) examined the learning effect of a simulation game in experiential education. Several other studies also included experiential science as a main subject in their studies (Bressler \& Bodzin, 2016; Pappa \& Papadopoulos, 2019; Scalise \& Clarke-Midura, 2018; Sung, Hwang, Wu, \& Lin, 2018; Wang \& Nunes, 2019). The second RQ was related with the examined topics. The findings of this review study indicated that learning/academic achievement was the most examined topic in articles. Similar to this finding, Calderón and Ruiz (2015) informed that nearly half of the studies examined the learning effects of the serious game. Additionally, Arici et al. (2019) revealed based on the content analysis of AR practices in science education that learning/academic achievement was the most examined variable in the articles.

The third RQ was related with the research methodologies. According to the findings, more than half of the articles preferred quantitative research design. This finding affirms the dominancy of quantitative research in serious game related studies in education (Arici et al., 2019; Boyle et al., 2016; Cheng et al., 2015; Connolly et al., 2012). The further analysis also showed that quasi-experimental research method was the most preferred experimental method in quantitative studies. Boyle et al. (2016) supported this finding by explaining that quasi-experimental was the most used study design in both entertainment games and learning games. The interesting finding of this study was the increasing trend of review/meta-analysis studies. Based on the findings, review/meta-analysis studies were implemented more than qualitative 
studies. This can be linked to the need of more review studies to better analyze the use of serious games in science education. While qualitative studies were less commonly used in research studies (Arici et al., 2019; Connolly et al., 2012), it can be commented that the researchers tend to use more review studies to reflect the procedures, implications and methods on the use of serious games in science education.

The fourth RQ was related with the most preferred data collection tools. The findings of this study showed that achievement tests and questionnaires were the most common used data collection tools. Similar to this finding, Arici et al. (2019) and Calderón and Ruiz (2015) mentioned about the substantial use of achievement tests and questionnaires. Based on the findings, game sessions were also used as data collection tools in numerous articles. This can be related with the need of understanding players' experiences or behaviors during the serious game play. The fifth RQ was related with the most preferred sampling methods, sampling groups and sample sizes. Regarding the use of sampling methods, convenience sampling was the most emphasized sampling method. The reason of applying convenience sampling more than random sampling can be related with the nature of convenience sampling allowing easy access to the reachable sample sites in quantitative, qualitative and mixed designs. Considering the sampling groups, secondary $\left(9-12^{\text {th }}\right.$ grade) students and primary (5-8 ${ }^{\text {th }}$ grade) students were the common sampling groups included in articles published over the last five years. Similar to this finding, high school students were mainly selected as sample groups based on the several review studies (Cheng et al., 2015; Li \& Tsai, 2013). Additionally, primary students were also selected as sample groups in some review studies (Arici et al., 2019; Cheng et al., 2015). For the sample sizes, 31-100-person group was the most used sample size in the articles. The sixth RQ was related with the most preferred data analysis methods. Regarding the data analysis methods, frequencies/percentages/tables and means and standard deviations as descriptive analyses methods were the most commonly used. On the other hand, inferential analyses methods, such as ANOVA/ANCOVA and correlations were also used in a large number of articles.

The seventh RQ was related with game types. Based on the findings, computer games were the most frequently used game type. Several review studies in the literature revealed the dominancy of computer games in educational serious game studies (Boyle et al., 2016; Calderón \& Ruiz, 2015; Cheng et al., 2015; Connolly et al., 2012). The interesting finding related to game types was the small number of mobile games integrated into serious game studies in science education. This can be linked to the limited use of smart phones in formal educational settings. The findings also indicated that AR and VR games were studied in very small number of articles published from 2016 to 2020. It can be inferred from this finding that there is a big need for investigating the immersive technologies integrated serious games in science education. The last $\mathrm{RQ}$ was related with game genres mostly preferred in the articles. With regard to the game genres, the findings showed that adventure was the most commonly selected genre in serious games. On the other hand, sport and simulations, RPG and puzzle games were included in small number of articles. However, racing, strategy and platform games were preferred only in 1 article. Similar to these findings, Cheng et al. (2015) found in the review study that adventure or role-playing game was the most common game genre, followed by simulation game and puzzle game. It can be concluded that more studies need to be conducted to better understand the common effect of serious games for different genres in science education.

\section{CONCLUSION}

This study aimed to conduct a systematic review of the use of serious games in science education. Based on the article selection process including inclusion and exclusion criteria, 39 articles published from 2016 to 2020 were listed. Main subject areas, examined topics, research methodologies, data collection tools, sampling methods and groups, sample sizes, data analysis methods, game types and game genres of these articles were analyzed for the systematic review. According to the results of analysis, experiential science was the most emphasized subject area of the articles. Additionally, learning/academic achievement was the most investigated topic. Regarding the research method trends, quantitative design was the most preferred one. For data collection tools, the majority of articles included achievement tests and questionnaires. With regard to the sampling procedures, convenience sampling was the most used sampling method. In addition, secondary $\left(9-12^{\text {th }}\right.$ grade) and primary $\left(5-8^{\text {th }}\right.$ grade) students were the common groups studied in the articles. 
Moreover, 31-100-person group was the most included sample size in the articles. Considering the data analysis methods, descriptive analyses methods were the most commonly used from 2016 to 2020 years. For the game types, computer game was the most frequently used one in the articles. With regard to the game genres, the large number of studies included serious games with adventure genre in articles published from 2016 to 2020 years.

The main objective of this review study was to reveal recent research trends on the use of serious games in science education. Based on the findings, several research suggestions can be offered. First, a variety of topics, such as misconceptions, interactions, flow, etc. should be examined more in research studies related with the use of serious games in science education. Second, more qualitative studies should be conducted to deeply understand the experiences related to use of serious games in science education. Third, the number of using game sessions as data collection tools should be increased to get a variety of data including game performance score, log value, reaction time, etc. Fourth, in addition to primary and secondary school students, different sample groups such as preschool children, disabled students and teachers should be integrated more into the research studies related with the use of serious games in science education. Fifth, computer games have been the popular game types in recent studies. Serious games integrating new immersive technologies, such as VR and AR technologies should also be investigated in science education. Sixth, mobile serious games should be included in more research studies in science education. Last, besides adventure games, the number of simulation, RPG, puzzle, etc. games should be increased to see the use and design issues of different genre of serious games in science education.

\section{REFERENCES}

Almeida, F. (2020). Adoption of a Serious Game in the Developing of Emotional Intelligence Skills. European Journal of Investigation in Health, Psychology and Education, 10(1), 30-43. https://doi.org/10.3390/ejihpe10010004

Alonso-Fernández, C., Martínez-Ortiz, I., Caballero, R., Freire, M., \& Fernández-Manjón, B. (2020). Predicting students' knowledge after playing a serious game based on learning analytics data: A case study. Journal of Computer Assisted Learning, 36(3), 350-358. https://doi.org/10.1111/jcal.12405

Alrehaili, E. A., \& Al Osman, H. (2019). A virtual reality role-playing serious game for experiential learning. Interactive Learning Environments, 1-14. https://doi.org/10.1080/10494820.2019.1703008

Arici, F., Yildirim, P., Caliklar, Ş., \& Yilmaz, R. M. (2019). Research trends in the use of augmented reality in science education: Content and bibliometric mapping analysis. Computers \& Education, 142, 103647. https://doi.org/10.1016/j.compedu.2019.103647

Baek, S., Park, J. Y., \& Han, J. (2016). Teacher assessment of simulation-based serious games for science education. International Journal of Serious Games, 3(3), 59-66. https://doi.org/10.17083/ijsg.v3i3.123

Boyle, E. A., Hainey, T., Connolly, T. M., Gray, G., Earp, J., Ott, M., ... Pereira, J. (2016). An update to the systematic literature review of empirical evidence of the impacts and outcomes of computer games

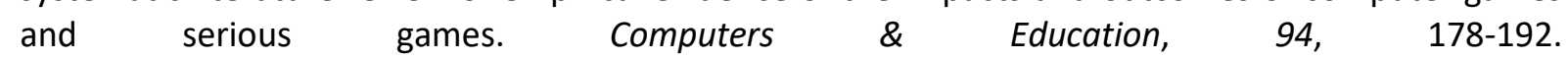
https://doi.org/10.1016/j.compedu.2015.11.003

Bressler, D. M., \& Bodzin, A. M. (2016). Investigating flow experience and scientific practices during a mobile serious educational game. Journal of Science Education and Technology, 25(5), 795-805. https://doi.org/10.1007/s10956-016-9639-z

Calderón, A., \& Ruiz, M. (2015). A systematic literature review on serious games evaluation: An application to software project management. Computers \& Education, 87, 396-422. https://doi.org/10.1016/j.compedu.2015.07.011 
Chang, C. Y., Kao, C. H., Hwang, G. J., \& Lin, F. H. (2019). From experiencing to critical thinking: a contextual game-based learning approach to improving nursing students' performance in Electrocardiogram training. Educational Technology Research and Development, 1-21. https://doi.org/10.1007/s11423019-09723-x

Charsky, D. (2010). From edutainment to serious games: A change in the use of game characteristics. Games and culture, 5(2), 177-198. https://doi.org/10.1177/1555412009354727

Cheng, M. T., Chen, J. H., Chu, S. J., \& Chen, S. Y. (2015). The use of serious games in science education: a review of selected empirical research from 2002 to 2013. Journal of Computers in Education, 2(3), 353375. https://doi.org/10.1007/s40692-015-0039-9

Connolly, T. M., Boyle, E. A., MacArthur, E., Hainey, T., \& Boyle, J. M. (2012). A systematic literature review of empirical evidence on computer games and serious games. Computers \& Education, 59(2), 661-686. https://doi.org/10.1016/j.compedu.2012.03.004

Girard, C., Ecalle, J., \& Magnan, A. (2013). Serious games as new educational tools: how effective are they? A meta-analysis of recent studies. Journal of Computer Assisted Learning, 29(3), 207-219. https://doi.org/10.1111/j.1365-2729.2012.00489.x

Goktas, Y., Kucuk, S., Aydemir, M., Telli, E., Arpacik, O., Yildirim, G., \& Reisoglu, I. (2012). Educational technology research trends in Turkey: A content analysis of the 2000-2009 decade. Educational Sciences: Theory and Practice, 12(1), 191-199.

Katsaounidou, A., Vrysis, L., Kotsakis, R., Dimoulas, C., \& Veglis, A. (2019). MAthE the game: A serious game for education and training in news verification. Education Sciences, 9(2), 155. https://doi.org/10.3390/educsci9020155

Li, M. C., \& Tsai, C. C. (2013). Game-based learning in science education: A review of relevant research. Journal of Science Education and Technology, 22(6), 877-898. https://doi.org/10.1007/s10956-013-9436-x

McBurnett, L. R., Hinrichs, M. M., Seager, T. P., \& Clark, S. S. (2018). Simulation gaming can strengthen experiential education in complex infrastructure systems. Simulation \& Gaming, 49(6), 620-641. https://doi.org/10.1177/1046878118767729

Pappa, D., \& Papadopoulos, H. (2019). A Use Case of the Application of Advanced Gaming and Immersion Technologies for Professional Training: The GAMEPHARM Training Environment for Physiotherapists. Electronic Journal of e-Learning, 17(2), 157-170. https://doi.org/10.34190/JEL.17.2.08

Poole, S. (2004). Trigger happy: Videogames and the entertainment revolution. Arcade Publishing.

Riopel, M., Nenciovici, L., Potvin, P., Chastenay, P., Charland, P., Sarrasin, J. B., \& Masson, S. (2019). Impact of serious games on science learning achievement compared with more conventional instruction: an overview and a meta-analysis. Studies in Science Education, 55(2), 169-214. https://doi.org/10.1080/03057267.2019.1722420

Scalise, K., \& Clarke-Midura, J. (2018). The many faces of scientific inquiry: Effectively measuring what students do and not only what they say. Journal of Research in Science Teaching, 55(10), 1469-1496. https://doi.org/10.1002/tea.21464

Sung, H. Y., Hwang, G. J., Wu, P. H., \& Lin, D. Q. (2018). Facilitating deep-strategy behaviors and positive learning performances in science inquiry activities with a 3D experiential gaming approach. Interactive Learning Environments, 26(8), 1053-1073. https://doi.org/10.1080/10494820.2018.1437049

Susi, T., Johannesson, M., \& Backlund, P. (2007). Serious games, an overview. Technical report HIS-IKI-TR-07001. University of Skvde. 
Vlachopoulos, D., \& Makri, A. (2017). The effect of games and simulations on higher education: a systematic literature review. International Journal of Educational Technology in Higher Education, 14(1), 22. https://doi.org/10.1186/s41239-017-0062-1

Wang, M., \& Nunes, M. B. (2019). Matching serious games with museum's educational roles: smart education in practice. Interactive Technology and Smart Education, 16(4), 319-342. https://doi.org/10.1108/ITSE03-2019-0013

Correspondence: Nuri Kara, Istanbul Bilgi University, Turkey. E-mail: nuri.kara@bilgi.edu.tr 